\title{
LA NECESARIA REFORMA DE LA UNIVERSIDAD ESPAÑOLA
}

\author{
MANUEL ARENILLA SÁEZ
}




\section{SUMARIO}

1. OBJETIVOS Y ACTORES DEL SUE. 2. DIAGNÓSTICO GENERAL. 3. LA AUTONOMÍA UNIVERSITARIA. 4. LAS BASES DEL MODELO DEL SUE Y SU APARENTE UNIFORMIDAD. 5. LOS ÓRGANOS DE GOBIERNO. 6. EL PERSONAL DE LA UNIVERSIDAD. 7. CONCLUSIONES Y PROPUESTAS. 7.1. La autonomía universitaria. 7.2. La gobernanza universitaria. 7.3. Los cargos académicos y el personal. 7.4. Endogamia, retribuciones, oferta de titulaciones y alumnos. 7.5. Evaluaciones, rankings y financiación. 


\title{
LA NECESARIA REFORMA DE LA UNIVERSIDAD ESPAÑOLA
}

\author{
MANUEL ARENILLA SÁEZ ${ }^{1}$ \\ Universidad Rey Juan Carlos
}

\section{OBJETIVOS Y ACTORES DEL SUE}

La primera cuestión que se va a considerar es si están definidos los objetivos del Sistema Universitario Español (SUE) con el fin de que todos sus actores puedan saber lo que se espera de ellos y hacia dónde deben encaminar su actuación. Para ello debería bastar extraer los objetivos de las normas y los diferentes acuerdos, informes y propuestas sobre la universidad española. En la Ley Orgánica de Universidades de 2001, de 21 de diciembre encontramos referencias a sus metas principales en los artículos $1.2,31,39$ y 41.1 y 3 (garantía de calidad, investigación y transferencia del conocimiento, fomento de la investigación, del desarrollo científico y de la innovación tecnológica) ${ }^{2}$. Los objetivos reflejados en esos documentos pueden resumirse en: compromiso con el servicio público (acceso universal y no discriminación por motivos económicos y sociales); compromiso con la sociedad y el desarrollo económico (responsabilidad social, formación a lo largo de la vida, transferencia de conocimiento, valores democráticos, inclusión, desarrollo sostenible, promoción de emprendedores); internacionalización y mejora de la competitividad (abrir las universidades, mejora de la producción científica, incremento de las patentes, estar visibles en el mapa europeo e internacional, crear un entorno académico y de innovación); especialización y diferenciación de las universidades (perfiles distintivos en las universidades, menciones de calidad a los másteres y doctorados); y Pacto de Estado en materia universitaria y de investigación (coordinación entre comunidades autónomas, las universidades y el tejido económico, social e institucional).

1 Catedrático de Ciencia de la Administración. Departamento de Derecho Público I y Ciencia Política. Universidad Rey Juan Carlos I. Campus de Vicálcavo, Paseo de Artilleros. 28032 Madrid. Email: manuel.arenilla@urjc.es ORCID: https://orcid.org/0000-0002-7533-8896

2 A estas metas hay que añadir las recogidas en el artículo 1 por lo que respecta a la promoción de la investigación, el desarrollo experimental y la innovación de la Ley 14/2011, de 1 de junio, de la Ciencia, la Tecnología y la Innovación (BOE del 2 de junio), 
Las bases de estos objetivos se asentaron en los acuerdos de la Estrategia de Lisboa en 2000 de la Unión Europea y en la declaración de Bolonia de 1999³. Sin embargo, a decir de las propuestas de las comisiones de expertos, la última de febrero de $2013^{4}$, y de los datos actuales del SUE, no se han alcanzado suficientemente los objetivos en materia de equidad social efectiva ${ }^{5}$, de calidad, de universidades de excelencia, de empleabilidad, de diversidad, de apertura interna e internacional, de selección de los mejores, de simplificación de la burocracia, de rendimiento en la investigación, de servicio a la sociedad, de duplicidad de títulos, etc. Cabe entonces preguntarse: ¿a qué se ha orientado estos años el SUE?, ¿en qué ha tenido éxito?

Si aplicamos un enfoque de sistemas a la política universitaria y a los actores que intervienen en ella, se puede plantear la hipótesis de que, si la situación les produjera pérdidas inaceptables de manera prolongada, tendrían un importante incentivo para cambiar. De hecho, ha habido reformas en estas décadas que los integrantes del SUE han debido considerar suficientes y asumibles, aunque no hayan satisfecho los objetivos iniciales señalados. Estas reformas se han centrado especialmente en las cuestiones de acceso y carrera del personal docente e investigador (PDI), en la elección de los rectores, aunque poco o nada en la modificación de los sistemas de gobernanza en su conjunto, en especial en su modelo organizativo, o en el compromiso efectivo con la sociedad.

Este enfoque se completa con el institucional que divide a las instituciones públicas entre inclusivas y extractivas ${ }^{6}$. Las primeras favorecen la estabilidad económica, el crecimiento y la innovación, mientras que las segundas propician unas reglas de juego sesgadas en favor de una élite minoritaria. La universidad española, en general,

3 Vidal Prado, C. (2012), «El Espacio Europeo de Educación Superior y su implantación en las universidades españolas», Revista catalana de dret públic, 44, pag. 255 y ss.

4 Comisión de Expertos para la Reforma del Sistema Universitario Español. (2013). «Addenda de los profesores Óscar Alzaga Villaamil y Mariola Urrea Corres a los capítulos I y III del informe denominado «Propuestas para la reforma y mejora de la calidad y eficiencia del sistema universitario español».

5 Comisión Técnica de Gobernanza Universitaria. (2011). «Diagnóstico, informe técnico-jurídico y propuestas de actuación en relación con las estructuras organizativas internas de las universidades españolas (gobernanza universitaria). Documento para análisis de la Comisión Mixta de Gobernanza Universitaria»

6 North, Douglas Cecil. (1990). Institutions, Institutional Change, and Economic Performance, Nueva York; Cambridge University Press; Levitsky, Steven y Murillo, María Victoria (2010), «Variación de la fortaleza institucional», en Revista de Sociología No 24; Spiller, Pablo T. y Tommasi, Mariano. (2007). The Institutional Foundations of Public Policy: A Transactions Theory and an Application to Argentina. Cambridge, UK: Cambridge University Press; Quality of Government Institute. (2010). «Measuring the quality of Government and subnational variation». Report for the European Commission Directorate-General Regional Policy, Directorate Policy Development. Estocolmo: Department of Political Science, University of Gothenburg; Acemoglu, Daron y James A. Robinson. (2012). Why nations fail: the origins of power, prosperity and poverty. London: Profile; Arenilla, Manuel. (2019) «La arquitectura institucional y el cumplimiento de la Agenda 2030 en Iberoamérica». Revista Reforma y Democracia, $\mathrm{n}^{\circ} .75$. 
puede incluirse entre estas segundas. El enfoque concluye en que las variables institucionales y su fortaleza condicionan el desarrollo económico y social, la gobernanza, el rendimiento de las organizaciones públicas, la confianza política, la confianza social y la satisfacción con la democracia. En el caso de la universidad española esto supone que su actual modelo de gobernanza es probable que se oriente más a cumplir con los objetivos de las élites del SUE que con los objetivos que la sociedad ha depositado en ella.

Cabe preguntarse por las razones de que el SUE haya experimentado escasas alteraciones en su conformación en las últimas décadas. Una posible explicación puede residir en la dificultad de emprender una reforma que altere el statu quo de las élites universitarias y que a buen seguro requeriría de un largo proceso de negociación con resultados que probablemente no satisfagan a todas las partes implicadas. Además, es probable que la reforma otorgue escasos rendimientos políticos a la persona o grupo que la impulse y sí un elevado nivel de riesgo para su carrera.

La reforma del SUE es probable que choque con la habitual resistencia del Ministerio de Hacienda a incrementar los costes de personal, que resultarían una consecuencia casi inevitable de la reforma. Un ejemplo de esta tendencia es que las bases retributivas de los complementos específico (general, singular y docente) y de productividad (cargos académicos y sexenios) permanecen inalteradas desde $1989^{7}$.

Además, la reforma universitaria no aparece entre las principales preocupaciones expresadas periódicamente por los ciudadanos, que tampoco tienen, en general, capacidad para percibir la transcendencia en sus vidas de la política universitaria. Por otra parte, a partir de la reforma de $2007^{8}$, las autoridades ministeriales han ganado peso por lo que respecta a la aprobación de títulos oficiales universitarios y la selección del PDI funcionario (catedráticos y profesores titulares de Universidad), equilibrándolo con la capacidad autonómica de aprobar los centros, la oferta de titulaciones y la dotación de plazas, entre otros aspectos.

Las autoridades autonómicas universitarias han contribuido a que el modelo actual haya generado 344 campus universitarios y1.047 facultades y escuelas ${ }^{9}$. Este modelo parece satisfacer el principio de equidad entendido como cercanía al domicilio de los estudiantes y sus familias. Por otra parte, al considerarse la autonomía universitaria como un ámbito de ejercicio de las autoridades académicas, libera a los responsables autonómicos en buena parte de su responsabilidad por el rendimiento universitario. No obstante, estos se han constituido recientemente en la Conferencia de Responsables Autonómicos de Universidad e Investigación (CRAU) para obtener más

7 Fueron fijadas mediante Real Decreto 1086/1989, de 28 de agosto, sobre retribuciones del profesorado universitario (BOE del 9 de septiembre), posteriormente se introdujeron algunas modificaciones que afectaron, en lo sustancial, al profesorado asociado.

8 Efectuada por la Ley Orgánica 4/2007, de 12 de abril, por la que se modifica la Ley Orgánica 6/2001, de 21 de diciembre, de Universidades (BOE de 13 de abril).

9 Ministerio de Ciencia, Innovación y Universidades. (2019). Datos y cifras del Sistema Universitario Español. Publicación 2018/2019, p. 9 y 11. 
información y tratar de equilibrar el peso de los rectores. Cualquier incremento de recursos financieros planteado por los consejeros autonómicos de universidades chocará con la consejería de Hacienda respectiva y con sus compañeros de gabinete. En la actualidad ese incremento va encaminándose a la gratuidad de la matrícula o la reducción de las tasas universitarias, de las que se espera obtener réditos electorales, aunque es probable que afecte a la financiación de las universidades en el futuro.

Las autoridades académicas se ven favorecidas por un modelo que facilita la continuidad de los equipos más allá del límite de los 8 años de mandato máximo de los rectores, aunque, claro es, el modelo no garantiza la ausencia de sobresaltos. En cualquier caso, el modelo permite crear amplias coaliciones de intereses. Estas requieren una compleja estructura de cargos académicos y de gobernanza que está dominada por numerosos órganos colegiados, muchos formados por elección de la comunidad universitaria, que se rigen por acuerdos basados en el mínimo común denominador de sus integrantes, lo que no favorece el cambio ni la innovación. Además, la autonomía universitaria les permite una negociación, aunque desigual, con el poder político, que suele quebrar en las cuestiones que tienen que ver con la financiación del SUE público. Finalmente, cuando se contrapone la autonomía con una mayor financiación, que puede venir acompañada de más control de los resultados, hasta ahora ha vencido la concepción tradicional de la autonomía. El resultado es un nivel bajo de responsabilidad de los órganos académicos y de gestión y un elevado grado de amateurismo en esta ${ }^{10}$.

Por su parte el personal docente e investigador (PDI) está enormemente fragmentado por su escalafón y jerarquía. Además de participar en el autogobierno de su universidad, ha logrado un alto grado de endogamia que se cifra en que el 73,4\% del profesorado de las universidades públicas trabaja en el mismo centro en el que se doctoró, un 87,4 \% lo hace en la misma comunidad autónoma en la que se doctoró, y casi un $98 \%$ trabaja en el país, España, en el que se doctoró ${ }^{11}$. Esta endogamia supone que la carrera se realiza preponderantemente en la universidad de partida, lo que es un incentivo para implicarse en las coaliciones de intereses que la gobiernan con el fin de progresar en la carrera.

Las universidades privadas se mueven entre la necesidad de integrarse de una manera efectiva en el SUE para ganar influencia y de beneficiarse del insuficiente rendimiento docente de las universidades públicas ${ }^{12}$. Su interés está en captar recursos del sector empresarial y facilitar la colocación de sus alumnos en el mercado, lo que ha sido entendido por una parte de la sociedad como una ventaja competitiva frente

10 Comisión Técnica de Gobernanza Universitaria, ob. cit. pág. 97.

11 Ministerio de Ciencia, Innovación y Universidades, ob. cit., p. 109.

12 Según el U-Ranking de 2020, 7 de las 10 universidades españolas con mejor puntuación en docencia son privadas. En Pérez, F. y Aldás, J. (dir.). (2020). Indicadores sintéticos de las universidades españolas. U-Ranking 2020, Madrid, Fundación BBVA. 
a la universidad pública ${ }^{13}$. El resultado es la existencia de 36 universidades privadas, la atracción del 18,5\% de los estudiantes universitarios y unas buenas expectativas de crecimiento ${ }^{14}$.

La capacidad de influencia de la sociedad en la alteración del modelo es escasa. Una parte de la sociedad elude el SUE público en las universidades privadas o en el extranjero. Hay que advertir que esto tiene como consecuencia que una parte significativa de las élites del país pueden desentenderse de la enseñanza pública y de los valores públicos que representa, como la importancia de la movilidad social, la equidad, la inclusión, la representatividad o la diversidad ${ }^{15}$. Los alumnos tienen una posición temporal en el sistema, de paso, y sus intereses, en general, no están en el SUE sino en el empleo que le proporcione ${ }^{16}$. Claro es, están interesados en la calidad del sistema por lo que puede significar de mejores oportunidades para su futuro.

Las grandes empresas realizan alianzas con las universidades privadas que les garantizan la selección de sus futuros profesionales, que completarán su formación en la empresa en la que ingresen, y con las que acuerdan programas de $\mathrm{I}+\mathrm{D}+\mathrm{I}$ y de financiación. Además, en algunos casos, favorecen la captación de alumnos con talento provenientes de las clases socioeconómicas más desfavorecidas. Algunos de esos alumnos siguen encontrando la posibilidad de desarrollar sus capacidades y futuro con las todavía insuficientes becas del sistema público, que, en compensación, les ofrece un amplio número de campus universitarios cerca de su residencia. Las demás empresas, que son casi todas, buscan trabajadores competentes.

El resultado, siguiendo con el enfoque propuesto, es la disparidad de intereses y el mantenimiento del modelo con periódicos ajustes que no lo alteran en lo sustancial, ya que los que tienen capacidad para cambiarlo, no obtienen ganancia en hacerlo, y los no favorecidos no tienen posibilidad de hacerlo o ya han buscado alternativas cuando es posible. Esto es lo que explica que las declaraciones realizadas por los actores con motivo de las elecciones a rector, de los cambios de los titulares del ministerio o de las consejerías de universidades o por los empresarios más relevantes del país sean congruentes con la situación descrita: los rectores piden más autonomía y financiación

13 En el estudio n 2662 de 2006 del CIS se recoge que el 37,1\% de los encuestados señalaba que la universidad privada proporciona a sus alumnos una enseñanza de mayor calidad frente al 30,5\% que opinaba que lo hacía la pública; un $34 \%$ señalaba que la privada proporcionaba una enseñanza más adaptada al mundo de hoy frente a un $24 \%$ que opinaba que lo hacía la pública. Centro de Investigaciones Sociológicas (2006). Barómetro de noviembre de 2006. Pérez, F. y Aldás, J. (dir.), ob. cit. p. 86.

14 Pérez, F. y Aldás, J. (dir.), ob. cit. p. 29.

15 Comisión de Expertos Internacionales. (2011). «Audacia para llegar lejos: universidades fuertes para la España del mañana. Informe de la Comisión de Expertos Internacionales de la EU2015», pag. 19-20.; Iglesias de Ussel, J, Miguel Rodríguez, J. de y Trinidad Requena, A. (2010). Sistemas y políticas de educación superior, Madrid, Consejo Económico y Social de España, p. 31 y 66.

16 El 81,6 \% de los encuestados señalan que la función del profesorado en la universidad es preparar para acceder y desenvolverse en el mundo laboral. Centro de Investigaciones Sociológicas (2013) Estudio $\mathrm{n}^{\circ} 2978$, Barómetro de febrero de 2013. 
sin un control mayor; las autoridades ministeriales o autonómicas universitarias solicitan acuerdos, nueva legislación, pactos y mejor rendimiento a los universitarios; las universidades privadas ganar peso en el SUE y fortalecer su posición en $\mathrm{I}+\mathrm{D}+\mathrm{I}$; el PDI una carrera mejor definida y el control sobre las plazas; el PAS mejoras en sus puestos de trabajo; y los empresarios adecuación a sus necesidades productivas. Los alumnos y sus familias siguen pidiendo trabajo al acabar, ya que el índice de paro de los egresados universitarios es muy elevado ${ }^{17}$.

En la situación descrita, el cambio puede venir por variar el peso y la posición de los actores actuales del SUE buscando las menores pérdidas a corto plazo mediante una reforma diseñada a medio y largo plazo. Para ello debe alcanzarse un consenso sobre los objetivos a lograr, que en la actualidad son diferentes para cada uno de los intervinientes en el SUE. Esto es debido a la falta de revisión en profundidad de un modelo universitario que respondía a una sociedad que ha evolucionado radicalmente en las últimas décadas.

\section{DIAGNÓSTICO GENERAL}

Las disfunciones del SUE entroncan con las del conjunto de la Administración española al formar parte la Universidad del mismo sistema político-administrativo. La primera consecuencia de esta afirmación es que para abordar cambios en profundidad en el modelo del SUE es preciso afectar a ese sistema, ya que los más importantes exigen un cambio radical de la cultura político-administrativa. Este pasa por gestionar por evidencias; planificar estratégicamente; orientar la actuación a la creación de valor público y social; reducir la burocracia y la organización administrativa; fortalecer la profesionalización del empleo público; potenciar la función directiva; introducir la evaluación de órganos, instituciones y del rendimiento o desempeño de las personas; implantar la contabilidad analítica; favorecer la movilidad entre Administraciones; desarrollar la Administración digital; la colaboración público-privada y social; etc.

Las reformas universitarias en las últimas décadas ${ }^{18}$ en los principales países de nuestro entorno, en sintonía con las reformas administrativas generales, se han encaminado a potenciar los órganos unipersonales y activos frente a los deliberativos y colegiados; a fortalecer la gestión; a favorecer la flexibilidad, la diversidad y la especialización; a delimitar la función académica de la administrativa o de gestión; a vincular la financiación al cumplimiento de indicadores y al equilibrio entre la oferta

17 Instituto Nacional de Evaluación Educativa. (2019). Panorama de la educación Indicadores de la OCDE 2019. Informe español. Informe Preliminar, pág. 34 y ss. Disponible en https://www. educacionyfp.gob.es/dam/jcr:b8f3deec-3fda-4622-befb-386a4681b299/panorama\%20de\%20la\%20 educaci\%C3\%B3n\%202019.pdf

18 Iglesias de Ussel y Trinidad, ob. cit, pág. 34; Arenilla Sáez, Manuel (2012). La reforma de la universidad española: un análisis desde su gobernanza, pág. 137; OCDE. (2014). OECD Public Governance Reviews Spain: From Administrative Reform To Continuous Improvement. París: OCDE. 
y la demanda; a evaluar ampliamente los resultados; a fortalecer las decisiones nacionales en materia de recursos humanos; a potenciar la capacidad ejecutiva de los órganos de dirección; a que las partes interesadas en la Universidad incrementen su implicación en las estructuras decisionales sobre la gestión y en el control del gobierno, etc. En nuestro país, en general, este no es el camino que se ha seguido.

No obstante, en los países homólogos existen grandes retos que también nos afectan: dura competencia por atraer talento en todo el mundo, tanto de profesores como de estudiantes, que se ve agravada por la demografía; incremento del tiempo parcial en la docencia; deterioro de la cualificación internacional; inadecuada compensación retributiva; burocratización; incremento de la competencia global por la movilidad; incremento del prestigio y la demanda de las universidades privadas; enorme presión de los rankings internacionales; y el logro de la equidad social.

Por lo que respecta a la financiación, según los datos de la $\mathrm{OCDE}^{19}$, los principales rasgos en esta materia de nuestros país si se compara con la media de los países miembros de este organismo y de la UE 22 es un menor gasto en educación terciaria (que incluye la Formación Profesional de Grado Superior) y una menor financiación pública; incremento del número de alumnos, aunque se ha estabilizado en los últimos años; una mayor reducción del gasto por alumno en la educación terciaria entre 2010 y 2015; unas tasas académicas bajas; un reducido número de becas; y un gasto corriente superior en personal universitario.

A estos rasgos ese organismo añade otros de carácter general: una elevada matriculación de los jóvenes; una tasa de empleo inferior, especialmente de los nacidos en el extranjero; una menor diferencia de ingresos de las mujeres respecto de los hombres; una menor proporción de mujeres graduadas por primera vez; muy baja proporción de graduados por primera vez en estudios de grado y baja en máster; una reducida tasa de empleo en estudios de grado, de máster y de doctorado; unos menores niveles de ingresos de los egresados por trabajo a tiempo competo.

Se puede afirmar a la vista de los datos comparados que el SUE necesita mejorar en eficiencia, incrementar la financiación general, aumentar el número de becas y ayudas al estudio y afrontar muy seriamente el abandono y la empleabilidad de nuestros egresados. Estos rasgos vienen constatándose de forma casi invariable en las últimas décadas en los estudios, informes y propuestas realizadas ${ }^{20}$. La mejora de la eficiencia también es una necesidad para el conjunto de las Administraciones públicas españolas, para lo que se requiere indicadores de gestión y de impacto, medición, evaluación y comparación; aspectos que no están presentes de forma habitual en nuestra cultura político-administrativa.

No obstante, el principal rasgo que define el sistema de financiación del SUE público es que las universidades asumen insuficientemente la relación existente entre

19 OCDE. (2018). Panorama de la Educación. Indicadores OCDE. 2017. Nota país. España, París, OCDE; y OCDE. (2019). Education at a Glance 2019. OECD Indicators, París, OCDE.

20 Iglesias de Ussel y Trinidad, ob. cit, pág. 56. 
la financiación pública de los servicios que prestan y la calidad de los mismos ${ }^{21}$. Existe una falta de corresponsabilidad financiera que dificulta el buen gobierno y la orientación a las necesidades y expectativas de los usuarios y de la sociedad, agravando de esta manera el riesgo sistémico del SUE público que es incumplir su función social. Se cae en este riesgo cuando los actores universitarios no perciben que exista y creen que solo hay una manera de actuar posible, aquella que mantiene el modelo actual. Este tipo de comportamiento es coherente con organizaciones diagnosticadas como extractivas, endogámicas y corporativistas. Finalmente, una de las señales de que el SUE público se ha adentrado en una zona de alto riesgo es que la sociedad busca alternativas, por ejemplo, en la docencia de las universidades privadas, en los departamentos y laboratorios de investigación e innovación de las grandes empresas y en los centros de investigación extranjeros.

Una baja conciencia de la necesidad de rendir cuentas a los financiadores -los ciudadanos que pagan los impuestos-, la falta de gestión basada en evidencias y en la evaluación de impacto en la sociedad, la orientación a objetivos internos y un modelo de gobernanza endogámico conducen a un sistema expansivo en términos financieros. Ante esta situación cabe preguntarse cuál es el incentivo de las instituciones reguladoras centrales y de las comunidades autónomas a incrementar o modificar la financiación del SUE, más allá de la gratuidad de la matrícula. También se advierte una cierta relajación de las autoridades autonómicas en la exigencia de resultados o el establecimiento de objetivos, más allá del establecimiento de planes plurianuales de financiación.

Algunos de los objetivos centrales del SUE parecen cumplirse, especialmente la igualdad de acceso a los estudios universitarios, tal y como se entiende en la actualidad, ya que la práctica totalidad de los jóvenes tienen la posibilidad de acceder a una universidad con actividad investigadora en un radio de 50 kilómetros de su domicilio familiar, lo que les permite su acceso diario al centro universitario ${ }^{22}$. Este logro, claro es, tiene evidentes efectos en la eficiencia del SUE y en la distribución de sus costes, ya que el $85,4 \%$ corresponde a gasto corriente, principalmente de personal $(66,7$ $\%)^{23}$.

Por otra parte, un eventual incremento de la financiación del SUE público no garantizaría automáticamente el debilitamiento de sus resistencias al cambio. Es cierto que se requiere una mayor dotación de recursos -especialmente en investigación- vinculados al cumplimiento de resultados y a la calidad de la docencia, la investigación y la transferencia tecnológica del PDI y de los distintos organismos universitarios; pero se necesitan también unos objetivos claros, un cambio en el modelo de gobernanza, una decidida y persistente dirección y liderazgo políticos, una

21 Peña Sánchez de Rivera, D. (2010). «Conclusiones». En Peña, D. (dir.). Propuestas para la reforma de la Universidad española, Madrid, Fundación Alternativas, pág. 146.

22 Hernández Armenteros, J. y Pérez García, J. A. (Dir.). (2018). La universidad española en cifras: 2016/2017, Madrid, Conferencia de Rectores de las Universidades Españolas, pág. 26.

23 Ministerio de Ciencia, Innovación y Universidades, ob.cit., pág. 105. 
reorientación a las verdaderas demandas de la sociedad, especialmente a la empleabilidad de los egresados, y la implicación de todos los actores en la transformación del modelo del SUE público.

En fin, este diagnóstico general concluye en que el actual modelo hace años que está agotado ${ }^{24}$.

\section{LA AUTONOMÍA UNIVERSITARIA}

Existen algunas claves que explican las dificultades para alterar el modelo del SUE; sin duda la más determinante es el concepto y el significado otorgado a la autonomía universitaria ${ }^{25}$. Nuestro ordenamiento constitucional la configura en el párrafo 10 del artículo 27 entre los derechos fundamentales más salvaguardados, ante cuya vulneración cabe el recurso de amparo. Las diversas sentencias del Tribunal Constitucional (TC), desde la STC 26/1987 de 27 de febrero ${ }^{26}$, señalan que su justificación es la de «asegurar el respeto a la libertad académica que garantiza y completa su dimensión individual, constituida por la libertad de cátedra» ${ }^{27}$. La finalidad es impedir que se dé una orientación ideológica determinada y que no exista ciencia ni doctrina oficiales, aunque esta libertad está sometida a la organización de las enseñanzas en las universidades ${ }^{28}$. La autonomía universitaria, en definitiva, es «expresión de su autogobierno, de auto-regulación, de autonomía financiera y de capacidad para desarrollar una línea docente e investigadora propia» (STC 44/2016, de 14 de marzo, FJ 4). No obstante, los aspectos de carácter más propiamente organizativo y de financiación aparecen claramente desdibujados y debilitados ${ }^{29}$, frente a la garantía estructural del contenido del derecho que se encuentra plenamente consolidada.

La concepción tradicional de la autonomía universitaria señala que las universidades públicas deben contar con todas las competencias necesarias para atender a su fin institucional, la libertad científica, evitando injerencias indebidas. Conlleva las potestades de auto-normación y de auto-organización, por lo que las comunidades

24 Peña Sánchez de Rivera, D., ob. cit, pág. 140.

25 Torres Muro, I. (2001). «La Autonomía Universitaria en la Jurisprudencia Constitucional Española», en Repertorio Aranzadi del Tribunal Constitucional, 3,

26 Consolidada posteriormente en las SSTC SSTC 55/1989, de 23 de febrero; 106/1990, de 6 de junio; 130/1991, de 6 de junio; 187/1991 y 156/1994, de 25 de abril.

27 Sosa Wagner, F. (2016). «La universidad española; entre Europa y una autonomía tramposa». Revista de Administración Pública, n 200, pág. 123.

28 Vidal Prado, C. (2008). »Libertad de cátedra y organización de la docencia en el ámbito universitario», Revista española de derecho constitucional, 84, pág. 75 y ss.

29 Cámara Villar, G. (2012). «La autonomía universitaria en España hoy, entre el mito y la realidad», Revista catala de dret public, núm. 44, pág. 103. 
autónomas no pueden ejercer control de oportunidad, de conveniencia o técnico sobre ellas ${ }^{30}$.

El alcance de la autonomía universitaria al PDI se concreta en «la naturaleza estrictamente académica de la selección y formación de plantillas del profesorado universitario» (STC 26/1987, de 11 de febrero, FJ 12), aunque dicha facultad no es absoluta, ya que "la selección del personal docente e investigador por cada universidad es uno de los ámbitos comprendidos en el contenido esencial de su derecho fundamental a la autonomía universitaria no se comporta como un límite absoluto que haga imposible cualquier intervención legislativa en ese ámbito» (STC 87/2014, de 29 de mayo, FJ 6).

Hay que señalar que el TC ha mantenido una posición ampliatoria del concepto de autonomía universitaria, que va mucho más allá de considerarla como garantía institucional, lo que ha reducido enormemente la capacidad del legislador, y aún del Tribunal Supremo, para establecer el marco de actuación de las universidades públicas. Los intentos de dotar de mayores competencias a los consejos sociales han chocado con la interpretación del TC, que no les otorga funciones académicas ni ningún predominio sobre la comunidad universitaria, en la que no les incluye. En definitiva, el TC ha otorgado el reconocimiento de un derecho fundamental a una institución pública $^{31}$.

La versión más generosa sobre la autonomía universitaria la concibe indisolublemente unida a la libertad de cátedra, que solo es tal para los profesores funcionarios - que así no están sometidos a una especial sujeción o dependencia ni a la jerarquía, como el resto de los funcionarios españoles_- esto es, para los catedráticos y profesores titulares de Universidad. Estos, según esta versión, gozan de una exención de trabas políticas y administrativas en el desempeño de su función docente e investigadora ${ }^{32}$.

Esta visión tradicional de la autonomía universitaria choca con la realidad del SUE, lo que hace que surjan las siguientes dudas: ¿Los PDI no funcionarios pueden recibir una orientación ideológica determinada y para ellos puede existir una ciencia y una doctrina oficiales? La respuesta es importante dado el gran volumen de ese tipo de personal y la previsión en los borradores que maneja el ministerio sobre el Estatuto del PDI de que se expanda y que muchos realizan las mismas funciones que los funcionarios, además de tener reconocidos prácticamente los mismos derechos. ¿A qué controles están sometidos el PDI? Si solo lo están a las normas que se aprueben en virtud de la auto-organización y auto-normación universitaria y al ethos individual, ¿Cómo se vincula su actuación y rendimiento con los objetivos generales de la política universitaria? Por otra parte, ¿quién es el titular del servicio público de la universidad? La contestación es relevante, porque la consecución de sus objetivos parece que

30 Comisión de Expertos para la Reforma del Sistema Universitario Español. (2013). «Propuestas para la reforma y mejora de la calidad y eficiencia del sistema universitario español».

31 Oliver Araújo, J. (1991) «Alcance y significado de la «autonomía universitaria» según la jurisprudencia del Tribunal Constitucional» Revista de Derecho Político, núm. 33, 1991, pág. 80.

32 Comisión de Expertos para la Reforma del Sistema Universitario Español, en su Addenda. 
debería corresponder a las universidades y a quienes las financian muy mayoritariamente mediante impuestos, las comunidades autónomas, que lo hacen en un 65,4 $\%^{33}$; si no hay duda de que es un servicio público el SUE público debería cumplir con los mismos requisitos que el resto de servicios públicos, muy especialmente el de la rendición de cuentas, el control ante los órganos representativos de los ciudadanos y el control de las entidades públicas reguladoras y financiadoras. En fin, la STC 5/1981, de 13 de febrero determina que la libertad de cátedra se atribuye a todos los docentes, independientemente de su nivel de enseñanza ${ }^{34}$.

Si se mantuviera una posición extrema de la autonomía universitaria cabe también preguntarse por el incentivo de las autoridades reguladoras y financiadoras del SUE público a introducir mejoras o a incrementar su financiación, más allá, por ejemplo, de la ya señalada gratuidad de las matrículas. Ante esta situación caben varias alternativas: que el TC varíe su doctrina tomando en consideración la evolución del SUE y los cambios transcendentes que se han producido en él, como, por ejemplo, la selección inicial y el progreso en la carrera del PDI, que ha quedado en buena parte fuera del ámbito de las universidades, y la evolución de la sociedad hacia un mayor control y rendición de cuentas de los servicios públicos. Otra alternativa es agotar el actual marco de interpretación de la autonomía universitaria empoderando a los consejos sociales, a los ejecutivos central y autonómicos y a los poderes legislativos. Finalmente, cabría mantener la situación actual y dejar que el sistema evolucionara inercialmente, lo que probablemente reforzaría los rasgos que lo caracterizan y las alternativas en el sector privado universitario o en el extranjero, aunque solo alcancen a una parte de la sociedad.

\section{LAS BASES DEL MODELO DEL SUE Y SU APARENTE UNIFORMIDAD}

La somera descripción que se ha realizado de los actores del SUE muestra que no existe una identidad de intereses y que no todos tienen la misma capacidad de influencia en el rendimiento del sistema. Se va a tratar de ahondar en las bases del modelo actual partiendo de la premisa de que, para alterar un sistema en aparente equilibrio, es conveniente que se ofrezca una alternativa a los actores que les incentive a modificar su posición; quizá la clave esté, como se ha señalado, en cambiar el peso de alguno de ellos.

El SUE de hace varias décadas se integraba en un modelo de Administración pública que prestaba escasos servicios públicos y se orientaba a formar principalmente a las futuras élites y dirigentes del país. En ese modelo, desarrollado en una dictadura y una sociedad jerarquizada, la equidad no era una preocupación importante, como tampoco lo era el rendimiento, que se remitía a lo que las distintas corporaciones

33 Ministerio de Ciencia, Innovación y Universidades, ob. cit. pág. 103.

34 Vidal Prado, C. (2008), ob. cit., pág. 64. 
públicas determinaran como más adecuado siguiendo su ethos particular. Esto favorece la consolidación de las élites extractivas en las instituciones.

Este modelo se resquebraja cuando, a partir de los años 60 del pasado siglo y más intensamente y con garantías democráticas tras la Constitución Española, se inicia un incipiente y no siempre consolidado Estado de Bienestar, que hace de la educación uno de sus pilares esenciales. En esta evolución, la enseñanza universitaria se convierte en un anhelo de progreso social y de igualdad para los españoles, pero no se ve acompañada de la financiación adecuada.

La transferencia a las comunidades autónomas permite convertir a la educación universitaria en una importante fuente de legitimación autonómica mediante la satisfacción de ese anhelo, que en el imaginario colectivo se cumple con los estudios universitarios y no con los de Formación Profesional hasta hace poco. El resultado es la confusión del principio de equidad con el de cercanía, aceptando, más o menos conscientemente, las consecuencias que la opción elegida puede tener en la equidad efectiva, en la promoción del talento y en la movilidad social. A esto hay que añadir que la creación del distrito único ha producido la existencia de comunidades autónomas «exportadoras» e «importadoras» de estudiantes a partir del 2000 al considerarse por la sociedad que hay determinados centros de mayor calidad. En estos casos, como señala la AIREF ${ }^{35}$, el sistema de becas de movilidad no es suficiente para una parte significativa de la población.

La Gran Recesión causa el abandono de la Estrategia Universidad 2015 española ${ }^{36}$ y los Objetivos de la Educación para la década 2010-2020 del Consejo Europeo y un retroceso en la financiación de los servicios educativos ${ }^{37}$. Los actuales compromisos europeos e internacionales adquiridos por España sobre el control del déficit y la deuda, la sostenibilidad financiera y el equilibrio presupuestario adquiridos antes de la actual pandemia cercenan las posibilidades de un crecimiento significativo de la financiación en los próximos años, salvo que sea a costa de otros bienes y servicios públicos o un incremento significativo de los ingresos universitarios. Estos difícilmente provendrán de fuentes privadas, ya que son más proclives a las universidades privadas donde tienen mucha mayor capacidad de control. El cuadro se completa con una situación económica muy complicada en el ámbito internacional debido a la crisis que está generando la COVID-19.

35 AIREF. (2018). «Estudio Becas de Educación Universitaria», Madrid, AIREF, pág. 15.

36 Ministerio de Ciencia e Innovación. (2009). «Estrategia Universidad 2015. Universidades para el progreso, el bienestar y la competitividad».

37 La aprobación del Real Decreto-ley 14/2012, de 20 de abril, de medidas urgentes de racionalización del gasto público en el ámbito educativo tuvo un fuerte impacto en las Administraciones públicas, especialmente en su empleo como señala Delgado Ramos, D. (2017). «La reforma de las Administraciones públicas en España (2012-2015)», en C. Vidal y D. Delgado (coord.). Crisis económicas y reforma de las Administraciones públicas. Un Estudio Comparado, Madrid, INAP, pág.140 y ss. Sus efectos alcanzaron, entre otros aspectos, al régimen de dedicación del profesorado universitario, a los precios públicos universitarios y a los ritmos de acceso a los diferentes cuerpos y escalas. 
La aparición del Estado autonómico contribuyó, con el apoyo de las élites universitarias, a producir algunos de los efectos que figuran en todos los diagnósticos sobre el SUE, como la proliferación de universidades, de centros universitarios y de titulaciones, así como la falta de especialización.

Como en otros servicios públicos, la Transición produce una cierta apertura de la forma en la que se adoptan las decisiones y se conforman los órganos universitarios, pero no altera sustancialmente la cultura, que sigue en buena parte anclada en un modelo tradicional del SUE y en sus principales actores que, con alguna incorporación, han logrado mantener el viejo equilibrio sin grandes pérdidas. Desde esta perspectiva, un cambio de modelo requiere revisar la misión, los fines, las metas y los objetivos, así como introducir una nueva forma de gobernanza y de gestión. Esto implica fortalecer la orientación a la creación de valor público y a rendir cuentas de manera efectiva a los financiadores públicos y a los legislativos autonómicos, sometiéndose a las evaluaciones y a las consecuencias correspondientes en materia de financiación. Por lo que respecta a la creación de valor público, este debe atender principalmente, siguiendo al Foro del Consejo de Europa, al desarrollo de la democracia, los derechos humanos, la cohesión social y el imperio de la ley, con la finalidad, tras la Agenda 2030, de no dejar a nadie atrás.

El modelo del SUE descansa también en una concepción uniforme de las universidades públicas. El margen de diferenciación que permite el marco normativo general apenas ha sido utilizado, salvo por unas pocas de ellas, lo que no impide que deba hablarse de que existen ya varias «ligas» de universidades, como se constata en los diversos rankings ${ }^{38}$, y que la tendencia sea a que se incremente la diferencia entre ellas: las de calidad, las especializadas en algún área de conocimiento y el resto dedicadas fundamentalmente a la enseñanza ${ }^{39}$. Indudablemente, este tipo de diferencias son de gran transcendencia para los alumnos y sus familias.

La concepción uniforme formal del SUE parece corresponderse con la existencia de un distrito único de movilidad interuniversitaria de alumnos. Sin embargo, las periódicas polémicas sobre el nivel de exigencia en las distintas comunidades autónomas en las pruebas de acceso a la Universidad, las diferentes puntuaciones en los sucesivos informes PISA según las comunidades autónomas, los diversos costes de las tasas, la impartición de las clases en otras lenguas oficiales del Estado distintas del castellano y la escasez de becas y ayudas al estudio, hacen que la movilidad sea reducida. Así, por ejemplo, el $22 \%$ de los beneficiarios iniciales de las becas no cambió de residencia porque no se lo pudo permitir ${ }^{40}$.

38 El U-Ranking del BBVA señala que las diferencias entre universidades son relevantes, ya. Las diferencias de rendimiento entre los Sistemas Universitarios Regionales son grandes: 38 puntos porcentuales entre la comunidad autónoma con mejor y peor resultado; en Pérez, F. y Aldás, J. (dir.). ob. cit. pág. 67.

39 Comisión de Expertos Internacionales, ob. cit. p 5 y 24.

40 AIREF, ob. cit., pág. 15. 
Ante esta situación, cabe preguntarse si no sería bueno introducir un mayor margen de flexibilidad en la organización y la gestión universitaria. Iría acompañado de los correspondientes estímulos ofrecidos por los gobiernos autonómicos y estatal con la finalidad de establecer su internacionalización y una verdadera competencia en el SUE con el fin de optimizar su rendimiento y retener y atraer el mejor talento.

\section{LOS ÓRGANOS DE GOBIERNO}

La configuración institucional de la gobernanza del SUE público responde al modelo que la determina. El actual se basa en el predominio de un complejo sistema de órganos académicos colegiados sobre los órganos unipersonales y que está compuesto por numerosos integrantes electivos que desempeñan funciones ejecutivas. En sus miembros concurre la condición de redactores, ejecutores y destinatarios de las normas y acuerdos adoptados en dichos órganos de gobierno. Esta conformación puede dificultar la organización racional del gobierno y favorece un posicionamiento proteccionista y una cierta pasividad u oposición frente a los posibles cambios. Además, los procesos de elección de los órganos de gobierno no favorecen la incorporación e integración de las demandas sociales ni la internacionalización ${ }^{41}$. Por otra parte, esta situación produce una cierta estabilidad, que alcanza a la carrera profesional, cuando se logran coaliciones duraderas de intereses y la integración de conflictos e intereses a través de los órganos representativos, aunque sea a costa de la pérdida de competitividad y de un significativo conformismo.

La figura del rector ha ido ganando peso con las distintas reformas, aunque la concepción del sistema de gobierno como una coalición de intereses y cuerpos haga que su capacidad ejecutiva sea, en general, reducida y necesariamente compartida. En la actualidad no se exige más requisito que ser catedrático de Universidad y pertenecer a la universidad correspondiente, cuyos integrantes lo eligen bien a través del claustro o por elección directa, atendiendo a los pesos de los diferentes sectores universitarios. De esta manera, para ser elegido rector, se requiere formar una coalición de apoyo con las distintas categorías del PDI, el PAS, los sindicatos y los alumnos y negociar con ellos las correspondientes compensaciones a cambio de los apoyos. Como se ha señalado, es muy difícil en este modelo de acuerdos de mínimos entre tantos y diversos intereses que fructifique o perdure la innovación y el cambio.

El claustro suele ser muy numeroso, lo que no impide que tenga asignadas algunas funciones ejecutivas. Su función es distinta si elige al rector o si es un órgano de

41 Tribunal de Cuentas. (2008). Informe de fiscalización de las universidades públicas. Ejercicio 2003. BOE de 4 de marzo de 2010, pág. 21157, 21162; Consejo de Universidades y Conferencia General de Política Universitaria (2010), «Documento de mejora y seguimiento de las políticas de financiación de las universidades para promover la excelencia académica e incrementar el impacto socioeconómico del Sistema Universitario Español (SUE). Eje de la estrategia universidad 2015», pág. 19-21; OCDE (2009), OECD Reviews of Tertiary Education. Spain. OCDE, París, pág. 130-132. 
control de un rector elegido por la comunidad universitaria. Su composición es reflejo del peso de los distintos sectores e intereses. En este punto cabe preguntarse en qué grado los distintos sectores (PAS, alumnos y los diferentes tipos de PDI) participan y se responsabilizan de la consecución de los objetivos del SUE, de la política universitaria y de cada universidad. Es claro que tienen papeles distintos en el rendimiento del sistema, que se suele medir esencialmente por la labor docente, investigadora y de transferencia de conocimiento cuya responsabilidad recae esencialmente en el profesorado. Es diferente intervenir en el proceso de obtención de los resultados, tener derecho a la participación en este y ser responsable del rendimiento. Así, por ejemplo, el PAS, como el resto de empleados públicos, posee otros cauces de participación en los asuntos que tienen que ver con sus condiciones de trabajo.

Hay que hacer notar que las decisiones que adopte el claustro presentan limitaciones al faltar una parte esencial del sistema universitario: los ciudadanos que son los que financian mayoritariamente el SUE. De esta manera, el claustro conforma la voluntad de la comunidad universitaria esencialmente en los aspectos académicos, pero no en todos los intereses en juego. Por eso no se debería considerar una injerencia una participación relevante de los intereses de los ciudadanos en el rendimiento del SUE público, sino el medio para lograr una legitimidad democrática plena de las universidades.

Junto a los órganos estrictamente académicos, encontramos al consejo social que se crea con la finalidad de fortalecer la legitimidad de una institución que gasta cuantiosos fondos públicos y que precisa de representantes sociales y económicos para saber si está cumpliendo con su compromiso social y su función pública y para reforzar su legitimidad democrática.

Todos los informes, incluso los menos proclives a un mayor peso de este órgano, coinciden en que no cumple con su función debido a los pocos instrumentos que tiene en su mano y su escaso efecto cuando son utilizados, por ejemplo, en materia presupuestaria $^{42}$. También coinciden en la necesidad de reducir su composición, en que lidere las estrategias de modernización del papel de la universidad en la sociedad, que realice propuestas para aproximar las titulaciones a las necesidades del sistema económico y se le asignen competencias en la aprobación de presupuestos y en materia de financiación.

Como se ha señalado, el consejo social, o el órgano en que se transforme, debe verse como el cauce principal para reforzar la legitimación democrática de la universidad pública y para conectar a los receptores de sus servicios y financiadores principales con su gestión y control. Por si esto no fuera suficiente, una de las características de las mejores universidades del mundo es que este tipo de órganos rinde cuentas ante la sociedad en su conjunto y no solo ante su comunidad universitaria.

42 Fundación CYD-CRUE (2010): «La gobernanza de la universidad y sus entidades de investigación e innovación», pág. 48-53. 


\section{EL PERSONAL DE LA UNIVERSIDAD}

El PAS y el PDI cumplen funciones muy diferentes en la consecución de los objetivos del SUE público. Para entender su papel es necesario basarse en el enfoque de la Ciencia de la Administración que diferencia entre las instituciones que son Administración pública y aquellas que tienen Administración. Las universidades públicas pertenecen a estas últimas. Así, la universidad tiene un aparato administrativo medial o de mantenimiento para cumplir los objetivos del servicio público que tiene encomendado. Ese aparato es medial no tiene atribuidos los fines de la institución, sino que ayuda a cumplirlos. Esto sucede también con otras instituciones, como las legislativas, las judiciales o algunas de supervisión o control, por ejemplo.

Lo que se acaba de señalar es de gran importancia para asignar al PDI y al PAS su papel en las universidades. El segundo facilita, en general, las funciones del primero con el fin de cumplir los objetivos centrales que la universidad tiene atribuidos. Es cierto que la labor del PAS es fundamental para lograr la eficacia en la consecución de los resultados y que tiene un papel importante en la consecución de la calidad y el rendimiento del sistema, pero no tiene el mismo grado de responsabilidad social que el PDI. Debido al papel que el PAS cumple en la consecución de los objetivos universitarios, debe tener garantizada una participación ajustada y adecuada en la comunidad universitaria, además del resto de los derechos de negociación y participación que corresponden a los empleados públicos.

Junto con lo anterior, y puesto que el PAS forma parte de una Administración pública de tipo medial, esta debe contar con todos los elementos que la caracterizan en nuestro ordenamiento jurídico, esencialmente la diferenciación del poder político de la institución, la neutralidad y la profesionalización de su personal. Muchos de los diagnósticos coinciden en que no siempre se dan estos elementos, antes bien, se constata una débil profesionalización de la Administración universitaria debido, principalmente, a que los puestos de dirección administrativa están ocupados por PDI; a una plantilla en situación precaria, tanto por su elevada temporalidad como por la elevada provisionalidad en la ocupación de los puestos, especialmente los superiores; y porque estos presentan una proporción muy reducida sobre el conjunto de la plantilla. A esto hay que añadir la rigidez de las relaciones de puestos de trabajo; la estanquidad de las plantillas de las universidades de una misma comunidad autónoma; la falta de movilidad interadministrativa; y la insuficiente regulación de las relaciones laborales del PAS que prestan servicios en actividades concretas de investigación en la universidad ${ }^{43}$.

Lo anterior se ve acompañado por la escasa utilización de herramientas y procedimientos de gestión avanzada como la evaluación del rendimiento, la valoración de

43 Consejo de Universidades y Conferencia General de Política Universitaria, ob. cit. pág. 70 y ss.; Ministerio de Ciencia e Innovación. (2009). «Estrategia Universidad 2015. Universidades para el progreso, el bienestar y la competitividad», pág. 43-4; OCDE (2009), ob. cit. pág: 102-103. 
puestos de trabajo, la contabilidad analítica, la gestión por competencias o los sistemas de medición de la eficiencia de la gestión; en esto participan de la situación general de las Administraciones españolas.

Una de las razones que puede explicar la situación del PAS y de la Administración universitaria es su posición en el sistema de gobernanza de la universidad. Su participación en la elección de los órganos unipersonales, especialmente del rector, puede ser decisiva. Forma parte de las distintas coaliciones de poder existentes en la universidad mediante los numerosos y fragmentados sindicatos que lo representan, lo que propicia el clientelismo y la confusión de su papel en el SUE público. Finalmente, este panorama facilita la politización o el clientelismo de los puestos superiores y la presión para incrementar los efectivos y las retribuciones, así como dificulta la incorporación de técnicas eficientes de gestión, como una mayor externalización de servicios de alta especialización que requieren una permanente actualización —innovación y servicios digitales - o, por el contrario, de poco valor añadido para la organización.

El concepto PDI engloba un colectivo muy fragmentado y con intereses muy distintos. Los catedráticos y profesores titulares representan el $45 \%$ de la plantilla, aunque si se tiene en cuenta su participación en la dedicación a tiempo completo es el $60 \%$. Definen a este colectivo su elevada edad media (más de 54 años) y su pérdida de peso en el conjunto del profesorado ${ }^{44}$. Este dato no representa en sí mismo un problema, sino que debe verse como una oportunidad para planificar la plantilla del PDI de los próximos 10 años y adecuarla a la demanda y a los objetivos establecidos para el SUE. El fortalecimiento de la laboralización en los borradores referentes al Estatuto del PDI hará cambiar significativamente el panorama actual de forma innecesaria.

Si nos atenemos a los rasgos de la selección y carrera del PDI, hay que comenzar señalando que el modelo español de acreditación configura un sistema de carrera horizontal a partir de la categoría de Ayudante Doctor, quedando la carrera universitaria escalafonada en tres categorías más, siendo las dos últimas de funcionarios. Todas estas categorías realizan las mismas funciones, aunque con carácter pleno las desempeñan los contratados doctores, los titulares y los catedráticos. Desde esta perspectiva, no tiene sentido atribuir la libertad de cátedra solo a los funcionarios.

El significado de lo anterior desde el punto de vista de la gestión de los recursos humanos es que existe una fuerte presión de los primeros escalones por alcanzar la cima de la carrera funcionarial, lo que se ve corroborado, por ejemplo, por el hecho de que la tasa anual de acreditación en los dos cuerpos de funcionarios es superior a la de reposición por jubilación o por otros motivos. Además, se constata en los últimos años el incremento de la contratación de profesores asociados en detrimento de las

44 ANECA. (2018). «Informe sobre el estado de la evaluación externa de la calidad en las universidades españolas 2017», Madrid, ANECA; Ministerio de Ciencia, Innovación y Universidades, ob. cit. 
figuras de Profesor Ayudante Doctor y profesor Contratado Doctor, lo que contribuye a la precarización del empleo ${ }^{45}$.

En los distintos cambios de modelo de selección y carrera se han producido etapas transitorias que han favorecido la integración de categorías inferiores en la inmediatamente superior sin realizar pruebas de selección y con el único requisito de ser doctor, como en la integración de los titulares de Escuela Universitaria en Titulares de Universidad. Este precedente obra en favor de posibles regularizaciones futuras ante el exceso de profesores acreditados, como ya realizan algunas universidades con algunas categorías. Los borradores que se encuentran en discusión sobre el Estatuto del PDI, al reordenar las figuras permanentes de entrada en el sistema, acentuarán esa tendencia histórica, que pone de manifiesto una inadecuación entre las vacantes y las acreditaciones.

También hay que constatar que la dedicación del profesorado público está absorbida por la obtención de las evidencias y en su formalización requerida por las agencias de acreditación desde que desean ingresar en la carrera universitaria. Esto les hace consumir grandes energías en tareas burocráticas, produce un sesgo acusado de su actividad hacia la investigación y les ancla en un sistema basado en la inseguridad permanente acentuada por unas bajas retribuciones. Debido a que el sistema realmente descansa en la contratación del profesorado por cada universidad y al sistema de gobernanza endogámico existente, la posibilidad real de realizar una carrera universitaria se produce esencialmente en la universidad de partida. Así, el 73,4\% del PDI trabaja en la universidad que leyó la tesis y el 87,4 \% en la comunidad autónoma donde la leyó ${ }^{46}$. Finalmente, el inicio de la carrera universitaria no está reservado necesariamente para los mejores, ya que existen varias maneras de iniciarla y el proceso lo que exige es acumular determinados méritos. Esta situación puede agravarse si se suprimiera o no se considerase obligatoria la acreditación a la categoría de Ayudante Doctor para iniciar la carrera en el SUE, lo que no queda suficientemente aclarado en los borradores señalados.

Hasta la introducción del sistema de acreditación del profesorado existía una equivalencia entre las necesidades de personal requerido por las universidades y las plazas ofertadas; incluso en el sistema de habilitación se ajustaba prácticamente a la realidad demandada. Hay que señalar que el desajuste entre oferta y demanda no existe en otro ámbito público español, caracterizado por la prohibición de que existan aprobados sin plaza. El efecto es la presión para la dotación de plazas, que se agrava con el gran número de profesores acreditados sin plaza, y una fuerte endogamia en cada universidad, que se ve favorecida porque resulta más económico promocionar a un profesor de la universidad que incorporar a uno de fuera ${ }^{47}$.

45 ANECA, ob. cit. pág. 113.

46 Ministerio de Ciencia, Innovación y Universidades, ob. cit, pág. 109.

47 Peña Sánchez de Rivera, pág. 146. 
Cuando se trata la cuestión de la internacionalización del profesorado, hay que sumar al coste de «importar» a un profesor de una universidad extranjera el coste que supone para el SUE, ya que un profesor español acreditado se quedará sin plaza. Añádase a esto el efecto político de esta «importación» en la elección de los rectores y otros cargos unipersonales y quizá podamos explicar la débil internacionalización de nuestro profesorado, incluso para atraer al español que presta servicios en universidades extranjeras. Es decir, el aspecto de la casi nula internacionalización (alrededor del $1 \%$ de la plantilla) podría explicarse por el modelo actual de gobernanza y de selección y carrera del profesorado.

También hay que referirse a la ocupación del PDI en las tareas de gestión de la universidad y a los méritos requeridos para la carrera del PDI. En ambos casos la función relegada es la docencia. En la carrera predomina la investigación frente a la docencia, que a su vez se ve postergada por la ocupación de puestos de gestión, que es considerada como mérito para la acreditación y que, en los borradores sobre el Estatuto del PDI, gana peso ${ }^{48}$. El resultado es la proliferación de cargos académicos; su interferencia con los puestos profesionales de la Administración universitaria, especialmente con los pertenecientes al personal de los grupos superiores de clasificación, al que sustituye en buena parte; la relegación de la función docente; y el incremento del profesorado contratado temporalmente. La propuesta de los borradores sobre el Estatuto del PDI implica la consolidación y agravamiento del actual modelo al contemplar la adquisición de méritos académicos para la carrera universitaria mediante la ocupación de cargos institucionales.

La relegación docente podría tener relación directa con el elevado fracaso o abandono universitario existente en el SUE y que es una característica significativa desde el punto de vista comparado. Así, la tasa total por abandono de estudios es del 33,3 $\%$; el $21 \%$ de los estudiantes se va de la universidad sin obtener el título; el coste anual del abandono es de 974 millones de euros; y las becas influyen modestamente en el rendimiento académico y en el abandono ${ }^{49}$.

Si el actual proyecto piloto del sexenio por méritos de transferencia continúa en el tiempo, hará que el profesorado se alinee con este incentivo, logrando un mejor rendimiento en la función social y económica de la Universidad. Indudablemente este incentivo será mucho más efectivo que cualquier declaración programática al respecto. Esto mismo ya ha sucedido con los sexenios de investigación cuando se vincularon al sistema de acreditación y de incentivos económicos. Quedaría pendiente mejorar el rendimiento de la función docente, de gran importancia en la consecución de la equidad y la movilidad social.

48 Ministerio de Universidades, ob. cit. pág. 44.

49 Pérez, F. y Aldás, J. (dir.). (2019). Indicadores sintéticos de las universidades españolas. U-Ranking 2019, Madrid, Fundación BBVA; AIREF, ob. cit; OCDE (2018), ob. cit. 


\section{CONCLUSIONES Y PROPUESTAS}

En muchos de los documentos recogidos en este artículo sobre la reforma del SUE se suele profundizar en su diagnóstico para dar paso a una serie de propuestas, aunque se echa en falta que se parta de una definición del modelo existente y de las alternativas, así como de los factores limitantes o barreras del cambio, así como los que propician o aceleran el cambio.

\subsection{La autonomía universitaria}

Entre los factores limitantes o barreras al cambio se encuentra el concepto de autonomía universitaria y su correlato de la libertad de cátedra. Es conveniente que se agoten las posibilidades que ofrece la vigente doctrina del TC para dar un mayor protagonismo a los ciudadanos, a través de los representantes institucionales que financian mayoritariamente el SUE público, y a la sociedad, mediante sus representantes económicos y sociales en los consejos sociales, con el fin de orientar el servicio público universitario a las necesidades de la sociedad y con ello ganar en legitimidad democrática. Este es el sentido de las reformas recientes en Austria, Dinamarca, Finlandia, los Países Bajos y Portugal.

Si los resultados del servicio público universitario inciden en la sociedad a través del desarrollo económico, el logro de la equidad y la movilidad social y el fortalecimiento de la democracia, parece lógico que las principales decisiones y los procesos de gestión que determinan esos resultados no queden preferentemente en manos de la comunidad universitaria, como sucede con cualquier otra política pública. Además, téngase en cuenta que las universidades dependen financieramente de las comunidades autónomas, como se ha reseñado, en casi dos tercios de sus ingresos. Por su parte, las tasas y precios públicos representan un 18,1\% del total ${ }^{50}$. El anuncio de la extensión de la gratuidad de las matrículas universitarias al SUE público reforzaría esa dependencia. Con estas cifras es necesario revisar el concepto de autonomía universitaria.

Una eventual reforma universitaria en profundidad habría de esperar, presumiblemente, a un nuevo pronunciamiento del TC, que debería tener en cuenta el tiempo pasado desde sus primeras sentencias, la realidad de la financiación universitaria y la profunda evolución de la sociedad española respecto al control de sus instituciones públicas en estas últimas décadas. En este sentido, el alcance de la libertad de cátedra, que se liga indisolublemente a la autonomía universitaria, debe tener en cuenta el gran peso del personal contratado en la universidad, su crecimiento y el hecho de que su sustancia se ve garantizada por otros derechos como la libertad ideológica, la libertad de expresión y el derecho a la producción científica y de compromiso del Estado

50 Ministerio de Ciencia, Innovación y Universidades, ob. cit, pág. 105. 
con una ciencia libre ${ }^{51}$. Esta ya no solo se produce en las universidades públicas, ya que existen grandes centros de investigación públicos como el CSIC y los organismos públicos de investigación (OPI) en el Estado y de los crecientes organismos equivalentes en varias comunidades autónomas, que representan más de la tercera parte del sistema de investigación público español. En fin, no es realista pensar que la libertad de cátedra solo alcance al personal funcionario, como no lo es que una universidad pública establezca directrices ideológicas a sus profesores contratados.

\subsection{La gobernanza universitaria}

La otra gran barrera en magnitud de importancia para que se produzca una mejora en el sistema universitario público es su modelo de gobernanza. Siendo coherente con el significado del derecho a la autonomía universitaria que se ha expresado, debe fortalecerse la cadena de responsabilidad y de rendición de cuentas en el gobierno de la universidad. Esta cuestión ha surgido en otros ámbitos, como en el caso de la Administración local española donde se han contrapuesto históricamente una visión corporativa, defendida desde posiciones iusnaturalistas, y una visión ejecutiva-representativa mantenida desde el compromiso con la eficacia y la transparencia y la consecuente responsabilidad de las decisiones de los órganos locales.

En unas instituciones locales elegidas democráticamente que gozan de autonomía y garantía institucional, fundamentada en tratados internacionales y en la Constitución, la tendencia en las últimas décadas es fortalecer los órganos unipersonales y los ejecutivos colegiados, especialmente en los grandes municipios, para que respondan ante sus plenos representativos y se sometan al creciente y permanente control de los órganos reguladores, fiscalizadores y de evaluación, tanto nacionales como de la Unión Europea, en los términos fijados en la ley. Los controles buscan lograr la eficiencia, la sostenibilidad financiera y el equilibrio presupuestario, así como la profesionalización de su organización, especialmente en su cúspide, que, hay que destacar, es seleccionada por la Administración General del Estado. Parece que cabría esperar algo similar, aunque adaptado a su tradición, de la universidad.

Para que se pueda afrontar con éxito los retos del SUE público es conveniente que se desarrollen las capacidades institucionales, la gobernanza y los recursos humanos bajo un fuerte liderazgo y una orientación a la eficiencia y la efectividad. Para ello es necesario reducir los órganos colegiados y su composición y limitar o suprimir sus competencias ejecutivas, especialmente las relacionadas con la planificación, las decisiones estratégicas, el presupuesto, la gestión y limitarse esencialmente al contenido académico con una orientación a la calidad docente y de investigación y a la generación de transferencia del conocimiento e innovación a la sociedad. Son tareas de gran importancia que requieren una cualificación que está fundamentalmente al alcance de la comunidad universitaria, esencialmente de los profesores e investigadores.

51 Comisión de Expertos para la Reforma del Sistema Universitario Español, ob. cit, pág. 8. 
El resultado sería la sensible reducción de los miembros de órganos como el claustro, las juntas de centro y departamento y órganos afines con el predominio en ellos del PDI y la eliminación o reducción significativa de las competencias exclusivas de gestión. En este aspecto, en la mayoría de las universidades, este tipo de órganos ya se limitan a hacer propuestas a los órganos centrales de gestión de las universidades. Este modelo se compensaría con el fortalecimiento de los órganos unipersonales y su dependencia jerárquica del rector, quien, es una posibilidad, podría nombrarlos con la participación de los órganos de representación o del consejo social de la universidad.

La propuesta de fusionar el actual consejo social con el consejo de gobierno creando el consejo de la universidad se viene produciendo desde hace varios años ${ }^{52}$. Los que están a favor de esta opción ponen énfasis, entre otros aspectos, en la simplificación del modelo actual; la ineficacia de los actuales consejos sociales, que realmente se conciben y funcionan como prácticamente ajenos a la comunidad universitaria; la necesidad de legitimar el servicio público universitario y mejorar su rendimiento; y en que es el modelo que siguen las mejores universidades del mundo.

Los detractores de esa fusión señalan, principalmente, que va en contra de la autonomía universitaria; que favorece la politización y el adoctrinamiento de las comunidades autónomas; y que impulsa la laboralización del PDI, lo que debilita la libertad de cátedra ${ }^{53}$.

Quizá se puede argumentar a los detractores de la creación del consejo de la universidad que la concepción actual de la autonomía universitaria genera una serie de barreras que han venido impidiendo las transformaciones requeridas por la sociedad para el SUE. Los actuales consejos sociales tienen escasas funciones en materia presupuestaria y de planificación, control y supervisión efectiva de la gestión universitaria en la ley, lo que no permite que las universidades sean permeables a las necesidades de la economía ${ }^{54}$. Por ello no es creíble que mejoren simplemente reduciendo sus miembros, incrementando su capacidad de hacer más propuestas o con reuniones con los órganos de la universidad, que es lo que se plantea para salir de su situación actual.

Es conveniente una reinterpretación menos academicista de la autonomía universitaria, que ya no puede ser considerada como un cuasi poder constitucional, que facilite el nombramiento de rectores responsables ante la sociedad y con plenas funciones ejecutivas que les permitan implementar un plan de gobierno para su universidad. Esto pasa por darle el peso adecuado a los representantes democráticos de los ciudadanos y a la sociedad con el fin de garantizar el efectivo cumplimiento de los fines públicos del SUE.

52 Ibíd, pág. 41.

53 Ibíd. pág. 24.

54 Fundación CYD-CRUE ob. cit. pág. 48-53. Comité de Expertos Internacionales, 2011: 27; OCDE, 2009: 103). 


\subsection{Los cargos académicos y el personal}

Por lo que respecta al PDI, si bien es cierto, que se han introducido modificaciones para mejorar los procesos de la ANECA, el sistema de acreditación se «ha visto afectado por graves problemas de burocratización y complejidad administrativa en los requisitos para la presentación de la documentación y un excesivo formalismo en sus trámites, lo que demanda su agilización para hacerlo más equitativo, garantista y eficaz» ${ }^{55}$. Sin embargo, no parece conveniente sustituir el sistema actual de acreditación del profesorado ya que la institución responsable de hacerlo está plenamente consolidada después de muchos avatares y su supresión es muy posible que nos retrotrajera a otras épocas de endogamia sin control. Bastaría con introducir correcciones significativas para atender a los defectos señalados, sustituir paulatinamente la presentación de la documentación del profesorado por una mayor proactividad de la ANECA sobre la base de la digitalización de los procesos; introducir el contraste de las aportaciones con entrevistas; y ajustar con un leve margen de holgura la demanda de las universidades de nuevas plazas a la oferta de las mismas, con el fin de evitar la injustificable bolsa actual de acreditados sin plaza. Algo de esto se contempla en los borradores del Estatuto del PDI.

Estas soluciones pasan por atribuir al ministerio competente en materia de universidades la estimación de la oferta global de vacantes por áreas de conocimiento atendiendo, entre otros aspectos, a la evolución de demografía, a la demanda de estudios de Formación Profesional de Grado Superior (que ya supera a la universitaria), a las plantillas universitarias y a las demandas de empleo existentes en la sociedad. Esta función la deberá realizar de acuerdo con las comunidades autónomas, con los consejos sociales y con los órganos de representación de las universidades. Este modelo debe replicarse en el escalón autonómico con las instituciones correspondientes para la acreditación de los profesores que no son competencia de la ANECA.

La contratación del profesorado no funcionario debe utilizar adecuadamente una de las figuras existentes para el acceso a la función pública como es el concurso. La finalidad es agilizar la incorporación del talento contrastado fehacientemente en nuestras universidades. Esta selección debe garantizar, además de los principios constitucionales establecidos para reclutar a los empleados públicos, una publicidad efectiva.

La internacionalización de nuestras universidades, de los titulares de sus órganos y del profesorado sigue siendo una necesidad en el SUE. Para ello es preciso convocar mediante concurso internacional la cobertura de determinados órganos unipersonales, como el rector y los titulares de los centros. Esto pasa por que el consejo de la univer-

55 Preámbulo del Borrador del Anteproyecto de Ley por la que se modificaría la Ley Orgánica 6/2001, de 21 de diciembre, de Universidades en relación con el estatuto del personal docente e investigador. Julio de 2020. 
sidad -y hasta su creación, por el consejo social- sea responsable o participe significativamente en su elección ${ }^{56}$.

Por lo que respecta a la selección del profesorado, debe favorecerse la incorporación de comunitarios a las plazas del PDI funcionario mediante el reconocimiento de los méritos ya acreditados en organismos europeos o internacionales equivalentes a la ANECA. Esto mismo cabe decir para el resto de las figuras del profesorado, incluyendo en este caso a los extranjeros no comunitarios pertenecientes a países con los que se firmen los convenios correspondientes de reciprocidad.

En los borradores del Estatuto del Personal docente e investigador y del Real Decreto del Estatuto del personal docente e investigador universitario de julio de $2020^{57}$ se perfila un nuevo modelo de ordenación de la carrera universitaria. Lo más destacado es la consolidación de la vía laboral paralela a la funcionarial para el PDI que se inició en la Ley Orgánica 11/1983, de Reforma Universitaria y que los borradores culminan al incluir a los catedráticos. Ambas vías coinciden en esta figura y en la de profesor titular, quedando en exclusiva para el ámbito laboral las nuevas de Profesores Profesionales Asociados, Profesores Doctores, Profesores Extraordinarios y Profesores Sustitutos Temporales.

La acreditación para las figuras de Catedrático y Titular se realizaría mediante la simplificación de los procesos y convierte el acceso a Catedrático en una promoción mediante un mecanismo automatizado. No se entiende la extensión de la dualidad de regímenes a las figuras de los cuerpos docentes funcionariales del PDI ya que los borradores establecen que el PDI contratado no podrá superar el 49 por ciento del total del PDI de la universidad, por lo que parece que se orienta a un predominio de los cuerpos funcionariales. Esta dualidad ya se ensayó en la función pública general a partir de 1984 con el fin de introducir una pretendida flexibilidad al sistema, con el resultado de reiterados procesos de funcionarización en todas las Administraciones públicas en las últimas décadas.

La reciente introducción del nuevo sexenio de transferencia para todos los campos de conocimiento empieza a dar carta de naturaleza a las orientaciones reales existentes del PDI: docencia, investigación y transferencia de conocimiento, aunque los borradores señalado también introducen, inadecuadamente, la gestión universitaria. El problema estriba en que en la actualidad solo existe un cauce de selección en el que se valora fundamentalmente la investigación. Parece evidente que un profesor no puede puntuar con un alto nivel de calidad en los tres perfiles, por lo que habrá que tener en cuenta su especialización. Esto plantea la cuestión de si debe haber investigadores «puros» que no impartan docencia. Como se ha señalado, esta se resiente en el modelo actual, por lo que habría que definir al PDI con un mínimo de docencia

\footnotetext{
56 Ibid, pág. 41.
}

57 Ministerio de Universidades. (2020). Borrador del Anteproyecto de Ley por la que se modificaría la Ley Orgánica 6/2001, de 21 de diciembre, de Universidades en relación con el estatuto del personal docente e investigador; y Borrador del Real Decreto del Estatuto del personal docente e investigador universitario. Julio de 2020. 
periódicamente evaluable, cuyo grado de dedicación estuviera vinculado a sus resultados en la investigación o la transferencia. Estas se medirían mediante sexenios para cada orientación o preferentemente mixtos para no desincentivar la investigación, especialmente en algunas áreas de conocimiento. Finalmente, la posesión de los sexenios se debería vincular a la ocupación de los cargos académicos y, por ejemplo, a los órganos de selección, evaluación o acreditación.

Por lo que respecta al PAS, además de lo ya señalado, es necesario que se aproveche la elevada tasa de jubilación actual para transformar en profundidad la gestión universitaria aprovechando las enormes posibilidades que ofrece la Administración digital. Para ello es preciso sustituir las vacantes que se produzcan en los grupos de titulación C1 y C2 generales por A1 y A2, incluyendo en este subgrupo a titulados especialistas de Formación Profesional de Grado Superior. Es conveniente incrementar y profesionalizar el estrato superior de personal de la Administración universitaria y hacerla depender de un gerente con una amplia autonomía de gestión sometida a evaluación periódica, que podría ser propuesto por el rector y designado por un futuro consejo de la universidad o el actual consejo social entre candidatos seleccionados por concurso sobre la base de competencias profesionales. Deben diferenciarse nítidamente las funciones académicas de las de gestión, que deben ser reservadas preferentemente al PAS, cuyos puestos deben ser provistos de manera pública y competitiva basada en competencias profesionales y cuyos ocupantes deberían someterse a una evaluación periódica.

\subsection{Endogamia, retribuciones, oferta de titulaciones y alumnos}

La endogamia en el SUE público se produce por varios factores. Uno de ellos es la financiación de las plazas para los acreditados, ya que es más económico contar con los profesores ya existentes en la plantilla que «importar» del exterior; a esto hay que añadir el modelo de gobernanza que hace que, para ser, por ejemplo, rector se necesite contar con el apoyo del profesorado que ya existe en la universidad. Estas dos causas se refuerzan mutuamente y hacen que un profesor al inicio de su carrera no tenga muchas posibilidades de obtener plaza fuera de su universidad.

Una posible solución es que el modelo basado en la acreditación se complete con comisiones de selección para los concursos cuya mayoría de miembros sea sorteada a nivel nacional para cada plaza. Sus miembros contarían con, al menos, tres sexenios de investigación. Estas medidas deberían acompañarse de la prohibición de contratar a doctores propios salvo que hayan estado, por ejemplo, algún tiempo fuera de su universidad. Además, habría que considerar desde una perspectiva estatal los efectos económicos de la movilidad del profesorado entre las universidades.

Las retribuciones del SUE público son bajas en todas sus categorías y muy bajas en las inferiores, tanto en términos comparados con otras profesiones de las Administraciones públicas españolas, incluidas las docentes no universitarias, como a nivel 
internacional. Además, el régimen de incompatibilidades, salvo para las áreas sanitarias, es muy estricto, lo que dificulta la transferencia de conocimiento, así como la movilidad con las universidades y centros privados. En fin, la base retributiva de los complementos específico y de productividad, que representan una parte muy significativa de la nómina, no se ha modificado desde 1989.

Es evidente que no pueden simultanearse bajas retribuciones y altas incompatibilidades salvo que estas se incumplan sistemáticamente, lo que incidiría negativamente en la integridad del profesorado y de la Universidad. La solución no es simple, ya que podría implicar un incremento notable de la financiación universitaria, acarrea un efecto de traslación retributiva a otros colectivos de empleados públicos y choca con la baja valoración que la opinión pública tiene de las instituciones públicas y de sus integrantes. Sin embargo, es preciso plantear un plan de mejora retributiva a medio y largo plazo, acompañado de la revisión del régimen de incompatibilidades, la generalización de la evaluación del rendimiento y su vinculación con las retribuciones y una decidida orientación a la eficiencia del gasto, con el fin de retener y atraer el talento universitario. Por otra parte, el incentivo económico ligado a la productividad investigadora, es realmente bajo. Finalmente, las retribuciones actuales dificultan sobremanera el retorno del talento emigrado a los centros universitarios extranjeros.

La oferta de titulaciones resulta claramente excesiva, costosa, ineficiente y desorientadora para la sociedad. En el curso 2017/2018 se impartieron 3.780 grados, 3.659 másteres y 1.137 doctorados en 344 campus $^{58}$. En buena parte es el resultado de optar por un sistema de registro de títulos que favorece su fragmentación, duplicación, solapamiento y desacoplamiento del mercado laboral entendiendo que así se fomenta la autonomía universitaria frente a un modelo de catálogo, como existió en su momento.

El actual sistema de aprobación y modificación de las titulaciones de grado y posgrado se caracteriza por su lentitud que es generada por una gran burocracia evaluadora. La iniciativa de la oferta descansa realmente en la voluntad de las universidades y en el juego interno de intereses. El papel planificador de la comunidad autónoma es realmente escaso, incluso en los momentos de fuertes restricciones como los recientemente vividos o con la creación de los Campus de Excelencia Internacional. Esto lleva a pensar que es conveniente alterar el peso de los actores que intervienen en la puesta en marcha de las titulaciones, incluir a otros y simplificar notablemente los procedimientos y tiempos de aprobación y revisión de los títulos.

La propuesta iría en la línea de aprobar marcos generales de titulaciones por áreas afines o familias de conocimiento con el fin de simplificar la oferta existente en los que participarían el ministerio de universidades, las comunidades autónomas, la ANECA, los órganos estatales de representación de las universidades y los consejos sociales. Esos marcos serían más flexibles en el caso de los posgrados. En un siguiente

58 Ministerio de Ciencia, Innovación y Universidades, ob. cit, pág. 11 y ss.. 
escalón las comunidades autónomas, junto con las universidades y los consejos sociales de su ámbito, diseñarían el mapa de titulaciones que quedaría vinculado a su financiación. Finalmente, cada universidad realizaría la propuesta para una titulación concreta atendiendo a las directrices de los escalones anteriores. La aprobación definitiva correspondería a la ANECA y a cada comunidad autónoma. El fomento de la competencia entre las titulaciones ofertadas por las universidades se orientaría a su calidad y a la adaptación real a las necesidades científicas, de la sociedad y del mercado.

Los alumnos determinan en buena medida la calidad de cada universidad y de sus titulaciones. La potestad de las universidades de seleccionar a sus alumnos mediante la nota de acceso a cada titulación determina en buena medida la atracción del talento de los alumnos. Es evidente que todas las titulaciones no pueden exigir una calificación alta para acceder a ellas, ya que las universidades públicas prestan un servicio público, lo que hace que el conjunto del SUE público deba posibilitar el acceso a la universidad pública a los solicitantes de plaza. El resultado es la existencia de universidades o titulaciones que captan alumnado con un elevado talento y otras no. Indudablemente este aspecto afecta al rendimiento de las universidades, a su posición en los rankings y, por ejemplo, al índice de éxito académico y a la captación de futuros PDI.

\subsection{Evaluaciones, rankings y financiación}

Más allá de lo que cada uno pueda pensar de los rankings, lo cierto es que, en la sociedad actual, donde contamos con una ingente e inabordable cantidad de información y en la que la exigencia social a las instituciones públicas es creciente, se necesitan prescriptores que orienten las decisiones individuales y colectivas. En un mundo globalizado, además cumplen la función de simplificar las transacciones y de homologar personas y organizaciones. Esta es la función de las instituciones que elaboran los rankings universitarios. Su validez estriba en su prestigio y en la aceptación por la comunidad de intereses afectados por los mismos y por la sociedad en general.

La universidad española ha introducido los sistemas de evaluación basados en indicadores de calidad para el profesorado y los títulos con consecuencias en la carrera y las retribuciones del primero y en la aprobación o eliminación de los segundos. Parece que es necesario que la medición, evaluación y comparación debe extenderse al resto de ámbitos universitarios: universidades, centros, departamentos e institutos, ya que todos ellos son artífices del rendimiento universitario, y no solo a los profesores de forma individual. Esta desagregación puede resultar beneficiosa al establecerse comparaciones a nivel internacional, como ya se realiza en algunas ocasiones, y nacional; para ello debe ser pública. Finalmente, los ciudadanos tienen derecho a conocer el valor público generado por el servicio público universitario que financian, vayan o 
no vayan ellos o sus familiares a la universidad. Por ello la función de los rankings es insustituible.

Una de las grandes carencias del sistema actual es la desvinculación del rendimiento de los profesores y los investigadores de la eficiencia en la consecución de los objetivos del SUE. En algunos casos, las comunidades autónomas incentivan, más allá de los sexenios de investigación, el logro de determinados resultados, pero suelen ser redundantes con los sexenios o priman la cantidad a la calidad. Es evidente que no puede haber una mejora en el SUE si no existe una identificación entre la calidad del rendimiento del profesorado y los objetivos del SUE. Para ello es necesario revisar el sistema de incentivos al profesorado y alinearlo con los objetivos que establezcan en el ámbito nacional y autonómico.

Con frecuencia, al tratar sobre rankings en el ámbito universitario surge la cuestión sobre cuál o cuáles elegir. En realidad, los principales rankings mundiales están aceptados por la comunidad universitaria internacional, por los medios de comunicación, por los financiadores y por el mercado. Este sería el caso, por ejemplo, de ARWU o de Shanghái y el QS; y entre nosotros el U-Ranking del BBVA y el de la Fundación CYD. Otra cosa es que cada uno presente sus sesgos correspondientes; muchos de ellos priman la investigación y la producción científica, como, por otra parte, hace entre nosotros, la ANECA en sus acreditaciones.

La cuestión no es si someterse o no a los rankings aceptados internacionalmente, lo que es indiscutible, sino qué está quedando fuera de su medición relacionado con el servicio público universitario. Probablemente para los aspectos directamente relacionados con este no medidos haya que establecer indicadores específicos y crear un ranking nacional por servicios ofertados con el fin de lograr, entre otros muchos beneficios, una mayor aceptación y legitimidad ciudadana al cumplir los fines sociales que tiene atribuidos. La forma de realizar ese ranking debe ser externa al SUE oficial, objetiva, sencilla y transparente.

Al igual que la evaluación del profesorado tiene consecuencias económicas, también debe tener consecuencias financieras la posición en los rankings de cada universidad. Para ello, las comunidades autónomas deben financiar a sus universidades según el cumplimiento de todos los objetivos del servicio público universitario determinados para cada ámbito territorial, teniendo en cuenta los rankings nacionales e internacionales. Esto posibilitaría introducir incentivos financieros para el cumplimiento de objetivos autonómicos y que se dotase de una financiación específica añadida al logro de metas de ámbito nacional. Los mecanismos de incentivos y desincentivos financieros es probable que sean más efectivos y eficientes que el recurso habitual a una exhaustiva regulación uniforme de carácter estatal.

La uniformidad reguladora responde a la aspiración de lograr una sociedad homogénea, que se asociaba al significado que se daba al principio de igualdad en el siglo XIX. Hoy lo propio de nuestra sociedad y de sus instituciones es la pluralidad y la diversidad. Estas ceden ante la garantía efectiva de los derechos de todos los ciudadanos y la existencia de un sistema político único en el Estado. De ahí que el funciona- 
miento de una universidad no puede desligarse del conjunto del SUE. Para ello hay que introducir la flexibilidad sobre la base de unos principios y un marco reducido pero suficiente de actuación común establecido y supervisado por las autoridades centrales. Este se ha de completar con un sistema de indicadores transparente y sometido a rendición de cuentas de base autonómica que manifieste el grado de cumplimiento de los objetivos del servicio público universitario y la posición nacional e internacional de cada universidad y, si es posible, de sus centros y títulos.

La introducción de la flexibilidad en el sentido señalado podría permitir que las universidades españolas puedan optar, durante el plazo que se considere conveniente, por un modelo de gobernanza más orientado al actual o de rector, con algunos de los cambios señalados, o al llamado de presidente, que adoptaría el modelo completo propuesto; por el diseño de títulos con contenidos y orientaciones más o menos innovadores; y por una selección de profesorado que mejore el talento de la universidad, para lo que podrían ofrecer incentivos económicos o de carrera.

Lo que sí parece claro es que la reforma universitaria no puede empezar por todos los aspectos a la vez. Es necesario determinar aquellos elementos que pueden generar transformaciones significativas a corto plazo y que no requieren grandes modificaciones normativas. Dada la situación política en la nos hemos asentado desde hace ya unos años, lo más prudente es comenzar por aquellas reformas que no exijan grandes cambios legislativos, sino retoques al modelo, por ejemplo, de la mejora y simplificación significativa de los procesos de la ANECA, de la selección del profesorado, una financiación alineada con el rendimiento del profesorado y de las universidades y sus órganos y la ampliación de las actuales competencias del consejo social con el fin de preparar a medio plazo, por ejemplo, la creación del consejo de la universidad. Esto requiere la elaboración de un calendario de actuación gradual acordado con los actores del sistema.

Finalmente, se pide prudencia para actuar de una manera efectiva a corto plazo, no para justificar quedarse en el diagnóstico y la reflexión; como en tantas ocasiones.

Title:

The necessary reform of the Spanish University

Summary:

1. Objectives and actors of the Spanish University System. 2. General diagnosis. 3. University autonomy. 4. The basis of the SUS model and 
its apparent uniformity. 5. The governing bodies. 6. University staff. 7. Conclusions and proposals. 7.1 University autonomy. 7.2 University governance. 7.3 Academic positions and staff. 7.4 Endogamy, remuneration, degree courses and students. 7.5 Evaluations, rankings and funding.

\section{Resumen:}

En las últimas dos décadas se han producido varias propuestas de reforma del sistema universitario español (SUE) mediante informes, libros blancos y todo tipo de documentos elaborados por organismos oficiales estatales, autonómicos, universitarios y por varias fundaciones. En ellas se han abordado todos los aspectos institucionales de las universidades; incluso se han constituido diversas comisiones de expertos a instancias de las autoridades ministeriales, con poco tiempo de diferencia entre ellas.

Las medidas adoptadas en el SUE no han servido para mejorar desde una perspectiva comparada el rendimiento docente, investigador, de innovación o de transferencia de conocimiento. Tampoco han mejorado suficientemente, por ejemplo, los niveles de equidad o la empleabilidad de los egresados de nuestras universidades. Finalmente, la situación del profesorado que se encuentra al comienzo de su carrera es preocupante.

En este artículo se presenta una propuesta de reforma del SUE desde la perspectiva de su gobernanza. Para ello, se tratará de discernir las metas a las que se orienta y el funcionamiento de los órganos universitarios. Finalmente, se expondrán los diversos actores existentes y sus interrelaciones.

Las principales conclusiones y propuestas de la investigación se refieren a la conveniencia de agotar las posibilidades que ofrece la vigente doctrina del Tribunal Constitucional para dar un mayor protagonismo a los consejos sociales; desarrollar las capacidades institucionales, la gobernanza y los recursos humanos bajo un fuerte liderazgo ejecutivo y una orientación a la eficiencia y la efectividad; transformar en profundidad la ordenación y la gestión universitaria y del personal de Administración y servicios (PAS); modificar y simplificar el modelo de acreditación con el fin de mejorar la eficacia, la internacionalización y la movilidad; así como vincular el rendimiento del personal docente e investigador (PDI) con la eficiencia en la consecución de los objetivos del SUE.

\section{Abstract:}

In the last two decades there have been several proposals to reform the Spanish university system (SUE). These have been proposed through reports, white papers and all kinds of documents drawn up by official state, regional and university bodies and by various foundations. They have addressed all the institutional aspects of universities; and even a number of committees of experts have been set up at the request of the ministerial authorities.

The recent measures taken in the SUE have not improved teaching, research, innovation or knowledge transfer performance from a comparative 
perspective. Nor have they sufficiently improved, for example, the levels of equity or the employability of graduates from our universities. Finally, the situation of teaching staff at early stages of their careers is worrying. This article discusses a possible reform the reform of the SUE from the perspective of its governance. To this end, SUE's goals will be identified and the preformance of the universities will be evaluated. Finally, the various existing actors and their relationships will be addressed.

The main conclusions and proposals of the research refer to the convenience of seizing every possibility offered by the current doctrine of the Constitutional Court to give greater prominence to social councils; develop institutional capacities, governance and human resources under a strong executive leadership and an orientation towards efficiency and effectiveness; transform in depth university planning and Administration and Services Staff (PAS) management; modify and simplify the accreditation model in order to improve efficiency, internationalisation and mobility; and finally, link the performance of teaching and research staff (PDI) with efficiency in the achievement of SUE objectives.

Palabras clave:

Universidad, España, gobernanza, innovación.

Key words:

University, Spain, governance, innovation. 
